\title{
Rhythmic expression of DEC2 protein in vitro and in vivo
}

\author{
FUYUKI SATO $^{1,2}$, YASUTERU MURAGAKI ${ }^{2}$, TAKESHI KAWAMOTO ${ }^{3}$, \\ KATSUMI FUJIMOTO ${ }^{3}$, YUKIO KATO ${ }^{3}$ and YANPING ZHANG ${ }^{1,4}$

\begin{abstract}
${ }^{1}$ Department of Radiation Oncology and Lineberger Comprehensive Cancer Center, School of Medicine, University of North Carolina at Chapel Hill, Chapel Hill, NC 27514, USA; ${ }^{2}$ Department of Pathology, Wakayama Medical University School of Medicine, Wakayama 641-8509; ${ }^{3}$ Department of Dental and Medical Biochemistry, Institute of Biomedical and Health Sciences, Hiroshima University, Hiroshima 734-8553, Japan; ${ }^{4}$ Jiangsu Center for the Collaboration and Innovation of Cancer Biotherapy, Cancer Institute, Xuzhou Medical College, Xuzhou, Jiangsu 221002, P.R. China
\end{abstract}

Received February 25, 2016; Accepted March 31, 2016

DOI: $10.3892 /$ br.2016.656

\begin{abstract}
Basic helix-loop-helix (bHLH) transcription factor DEC2 (bHLHE41/Sharp1) is one of the clock genes that show a circadian rhythm in various tissues. DEC2 regulates differentiation, sleep length, tumor cell invasion and apoptosis. Although studies have been conducted on the rhythmic expression of DEC2 mRNA in various tissues, the precise molecular mechanism of DEC2 expression is poorly understood. In the present study, we examined whether DEC2 protein had a rhythmic expression. Western blot analysis for DEC2 protein revealed a rhythmic expression in mouse liver, lung and muscle and in MCF-7 and U2OS cells. In addition, AMP-activated protein kinase (AMPK) activity (phosphorylation of AMPK) in mouse embryonic fibroblasts (MEFs) exhibited a rhythmic expression under the condition of medium change or glucose-depleted medium. However, the rhythmic expression of DEC2 in MEF gradually decreased in time under these conditions. The medium change affected the levels of DEC2 protein and phosphorylation of AMPK. In addition, the levels of DEC2 protein showed a rhythmic expression in vivo and in MCF-7 and U2OS cells. The results showed that the phosphorylation of AMPK immunoreactivity was strongly detected in the
\end{abstract}

Correspondence to: Dr Yanping Zhang, Department of Radiation Oncology and Lineberger Comprehensive Cancer Center, School of Medicine, University of North Carolina at Chapel Hill, 101 Manning Drive, Chapel Hill, NC 27514, USA

E-mail: ypzhang@med.unc.edu

Dr Fuyuki Sato, Department of Pathology, Wakayama Medical University School of Medicine, 811-1 Kimiidera, Wakayama 641-8509, Japan

E-mail: fsatodec1dec2@yahoo.co.jp

Key words: DEC2, circadian rhythm, phosphorylation of AMP-activated protein kinase, clock gene liver and lung of $D E C 2$ knockout mice compared with that of wild-type mice. These results may provide new insights into rhythmic expression and the regulation between DEC2 protein and AMPK activity.

\section{Introduction}

Circadian rhythms are important for living mammals and are predominantly regulated by clock genes (1-3). Disturbance of circadian rhythms may be associated with sleep disorder, depression, diabetes and cancer (4-9). A growing number of studies have shown that the abnormalities of clock gene expression are associated with psychiatric disorders, tumor progression, myocardial infarction, metabolic syndrome and immune disorder (10-16).

The transcription factor DEC2 is important in the circadian rhythm, hypoxia response, differentiation and tumor progression $(3,10,11,17-24)$. While DEC1 and DEC2 mRNA indicate a rhythmic expression in the suprachiasmatic nucleus (SCN), peripheral tissues, tumor cells and human mesenchymal stem cells (MSCs) $(3,17,18,21,25-29)$, whether DEC2 protein has rhythmic expression remains unclear. It seems likely that the rhythmic patterns of DEC1 and DEC2 are different in cell types (26), and what influences of DEC2 rhythmic expression under cell culture is poorly understood.

AMP-activated protein kinase (AMPK) is a sensor of cellular energy status $(30,31)$. AMPK activity (phosphorylation of AMPK or pAMPK) is important in glucose metabolism, cell death and tumor progression $(32,33)$. Rhythmic AMPK activity was observed in mice and mouse embryonic fibroblasts (MEFs) and a loss of AMPK disturbed the rhythmic expression of clock genes Bmall and Per2 (34,35). DEC1 protein and AMPK activity are known to have rhythmic expression in mouse liver, and DEC1 negatively regulates AMPK activity (36). However, the association between DEC2 and AMPK activity is unclear.

In the present study, we investigated the rhythmic expression of DEC2 protein and AMPK activity in mouse liver, lung and muscle, MCF-7 and U2OS human cancer cell lines, and MEF. These results may contribute to understanding of the 
biological functions of DEC2 and AMPK activity in various cell types.

\section{Materials and methods}

Animals. Six to 8-week-old male C57BL/6 mice were housed as previously described (26). The light in the mouse room was turned on at 7:00 a.m. (ZT 0 corresponds to 7:00 a.m., lights turned on) and turned off at 7:00 p.m. (ZT 12). Mice were entrained on a 12-h light/dark cycle for 2 weeks prior to experiments. Tissue samples were extracted from the liver, lungs and muscles of mice and were subjected to western blot analysis. Animal care and use procedures were approved by the Institutional Animal Care and Use Committee at the UNC at Chapel Hill Animal Care Facility.

DEC2 knockout mice. DEC2 $2^{-/}$mice were generated by inGenious Targeting Laboratory, Inc. (Stony Brook, NY, USA). Briefly, the 2.8-kb BsiEI-AlwNI genomic region of DEC2 that spans exons 1-5, including the entire coding region, was replaced with a Neo cassette. The knockout mice were backcrossed onto a C57BL/6 background. Six to 8-week-old mice were housed as above, and tissues were prepared for immunohistochemistry.

Immunohistochemistry. pAMPK immunoreactivity in mouse liver and lung tissues were evaluated using serial deparaffinized sections. Immunohistochemistry was performed using a Discovery auto-stainer machine with automated protocols (Ventana Medical Systems, Inc., Tucson, AZ, USA; Roche, Mannheim, Germany). Sections were reacted with pAMPK antibody (1:100) for $2 \mathrm{~h}$.

Cell culture and treatment. The MCF-7 human breast cancer and U2OS human osteosarcoma cell lines were obtained from the American Type Culture Collection (ATCC; Manassas, VA, USA). Primary MEF were prepared as previously described (37). The cells were cultured in Dulbecco's modified Eagle's medium (DMEM) (Sigma Chemical Co., St. Louis, MO, USA) or in DMEM without glucose (Gibco-Life Technologies, Grand Island, NY, USA) supplemented with $10 \%$ fetal bovine serum at $37^{\circ} \mathrm{C}$ in a humidified atmosphere of $95 \%$ air and $5 \% \mathrm{CO}_{2}$. The medium change (fresh medium) was performed at $0 \mathrm{~h}$, and the cells were cultured for 48 or $60 \mathrm{~h}$ without further medium change.

Antibodies. The following commercial antibodies were purchased: actin (mouse monoclonal, Ab-1; Millipore Corp., Billerica, MA, USA), DEC1 (rabbit polyclonal, NB100-1800; Novus Biologicals, Littleton, CO, USA), DEC2 (mouse monoclonal, E-4; Santa Cruz Biotechnology Inc., Santa Cruz, CA, USA), pAMPK (rabbit monoclonal, 40H9) and AMPK (rabbit monoclonal, 23A3) (both from Cell Signaling Technology, Inc., Danvers, MA, USA).

Western blotting. The cells treated with a medium change, or glucose-depleted medium were lysed using 0.5\% NP-40 lysis buffer for western blot analysis. The total cell lysates were run on $12.5 \%$ SDS-polyacrylamide gel followed by western blotting using the standard procedure. The WesternBright ECL and WesternBright Sirius kits (BioExpress, Kaysville, UT, USA) were used for antibody detection.
Data quantification. The intensities of the bands detected in Western blotting were quantified using Java based free software ImageJ (NIH, Bethesda, MD, USA).

\section{Results}

Rhythmic expression of DEC2 protein and pAMPK in mouse liver, lung and muscle. To investigate whether DEC2 protein and pAMPK showed a rhythmic expression in vivo, we performed western blot analysis using samples prepared from mouse liver, lungs and muscles at indicated ZTs. The levels of DEC2 protein and pAMPK showed a rhythmic expression (Fig. 1). A high level of total AMPK was detected in the liver, lungs and muscles at each time-point. These results suggested that DEC2 protein and AMPK activity have a rhythmic expression ubiquitously in various tissues.

Rhythmic expression of DEC2 protein by medium change in U2OS and MCF-7 cells. To determine whether medium change affected the rhythmic expression, we examined DEC2 protein levels in U2OS and MCF-7 cells. DEC2 protein levels in U2OS cells increased slightly at 18 and $24 \mathrm{~h}$ and the highest levels were observed at 42 and $48 \mathrm{~h}$ after medium change (Fig. 2A and B). DEC2 protein levels in MCF-7 cells strongly increased at $24 \mathrm{~h}$ and at 42-60 h after medium change (Fig. 2C and D). These results suggested that DEC2 protein is produced in a rhythmic manner by medium change. In addition, pAMPK in U2OS and MCF-7 cells increased in a time-dependent manner until $60 \mathrm{~h}$. A high level of total AMPK was observed in the MCF-7 and U2OS cells with a little alteration by medium change at each time-point. No rhythmic patterns were observed in pAMPK and total AMPK in the two cell lines.

Rhythmic expression of DEC2 protein by medium change in $M E F$. To investigate whether DEC2 protein was produced in a rhythmic manner in MEF, MEF was treated with medium change or glucose-depleted medium. Although DEC2 protein levels in MEF were decreased after medium change or glucose-depleted medium treatment (Fig. 3), rhythmic protein production was observed at 24 and $48 \mathrm{~h}$ after medium change. However, an obvious rhythmic pattern of DEC2 protein was not observed under the condition of glucose-depleted medium.

On the other hand, a rhythmic expression of pAMPK was evident in MEF following treatment with medium change and glucose-depleted medium, whereas total AMPK was constitutively produced without a rhythmic pattern under these conditions. In addition, DEC 1 protein levels began to decrease gradually $\sim 18 \mathrm{~h}$ after treatment with medium change or glucose-depleted medium. Thus, DEC1 in MEF had no rhythmic expression under these conditions.

$A M P K$ activity may be suppressed by DEC2. In a recent study, we reported that DEC1 negatively regulates AMPK activity (36). To investigate whether DEC2 regulated AMPK activity, we performed immunohistochemical detection of pAMPK in the liver and lung of DEC2 knockout mice using pAMPK antibody. The representative images of pAMPK immunoreactivity are shown in Fig. 4. Strong pAMPK was detected in the cytoplasm of the hepatocyte and sinusoid, and 
A

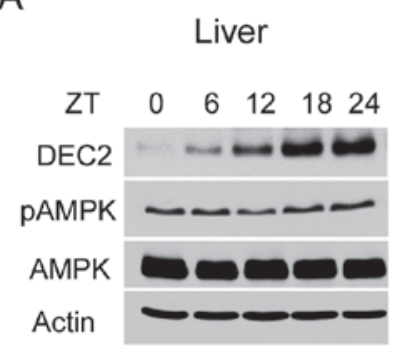

B
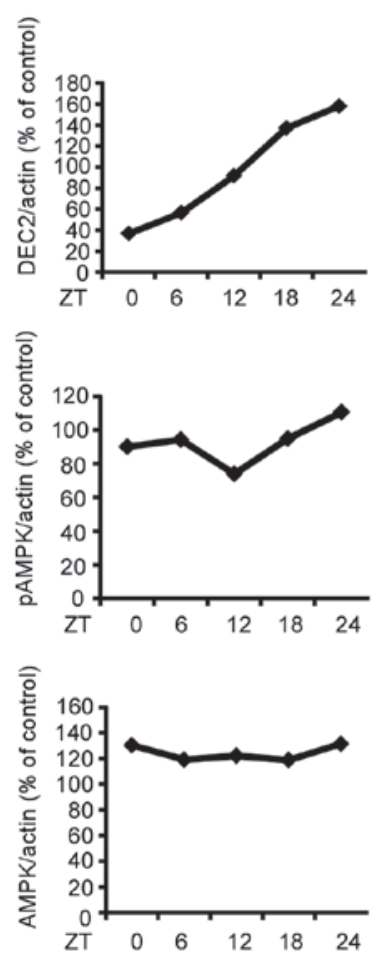

Lung
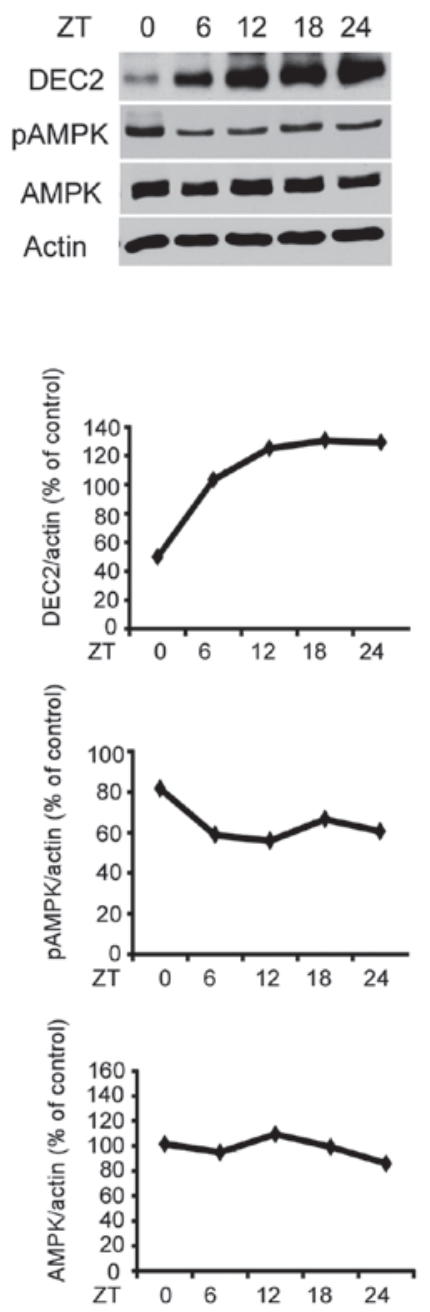

Muscle
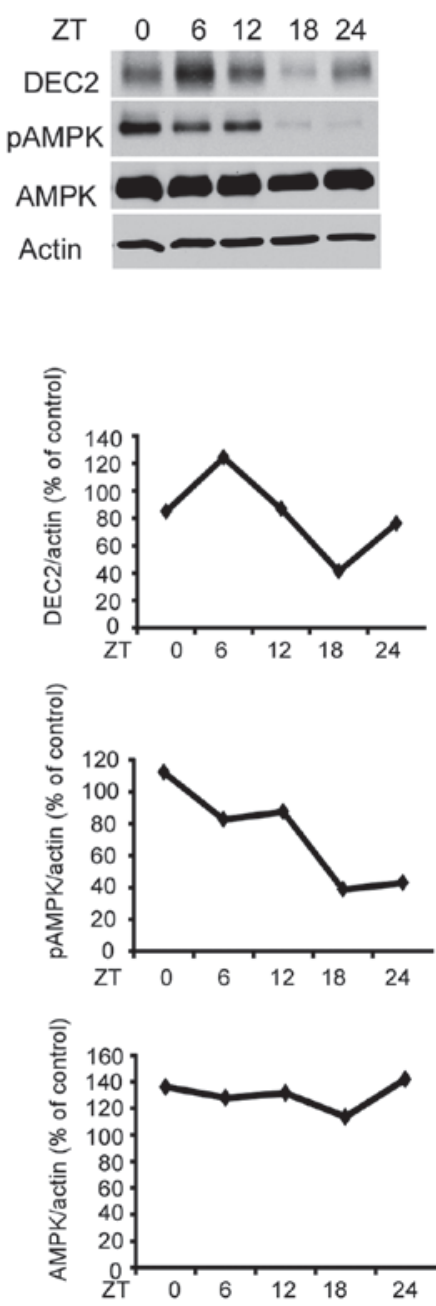

Figure 1. Rhythmic expression of DEC2 protein in mice. (A) Mice were housed under light-dark conditions as described in Materials and methods. Liver, lung and muscle samples were collected from the mice and subjected to western blotting for DEC2, pAMPK, AMPK and actin levels. One representative sample from two independent experiments with similar results is shown. (B) The intensities of DEC2, pAMPK and AMPK bands were quantified and divided by that of actin. AMPK, AMP-activated protein kinase.

in the cytoplasm of the alveolar epithelial and stromal cells of $D E C 2$ knockout mice compared with those of wild-type mice. It is therefore possible that $D E C 2$ may suppress AMPK activity.

\section{Discussion}

In the present study, we used differentiated and undifferentiated cells and tissues to compare the rhythmic expression of DEC2 and AMPK activity, to understand the biological functions of DEC2 in various cell types. DEC2 mRNA is known to show a rhythmic expression in SCN, kidneys, liver, muscles, sarcoma cells and hepatocellular carcinoma HepG2 cells $(3,21,25,38,39)$. However, there are no studies available on the rhythmic expression of DEC2 protein. Therefore, we focused on the expression levels of DEC2 protein. DEC1 was previously shown to have an inverted rhythmic pattern of AMPK activity in mouse liver and heart, binding to the E-box of the LKB1 promoter (36). Thus, DEC1 negatively regulates AMPK activity via LKB1 (36). DEC2 binds to the
E-boxes of the DEC1, PER1, PER2, MyoD, sterol regulatory element-binding protein-1c $(S R E B P-1 c)$ and DNA mismatch repair $(M M R)$ promoter $(3,18,40-43)$. The rhythmic expression of DEC2 in lung had an inverted pattern of pAMPK immunoreactivity. In addition, strong immunostaining of pAMPK was detected in DEC2 knockout mice tissues compared with those of wild-type mice. These results suggest that DEC2 regulates the metabolism of various tissues via AMPK activity.

Medium change in cultured rat-1 fibroblasts induces the rhythmic expression of PER2 and BMAL1, suggesting that medium change resets the circadian clock in cells (44). However, whether DEC2 expression is affected by medium change remains unclear. Therefore, we examined whether DEC2 has a rhythmic expression in cultured cells by medium change. As the endogenous expression of DEC2 was low in fibroblasts, we used two cancer cell-lines (MCF-7 and U2OS), as previously described $(21,45,46)$. We found that DEC2 protein levels showed a rhythmic expression by medium change. These results suggest that medium change induces 
A

U2OS

A

medium change
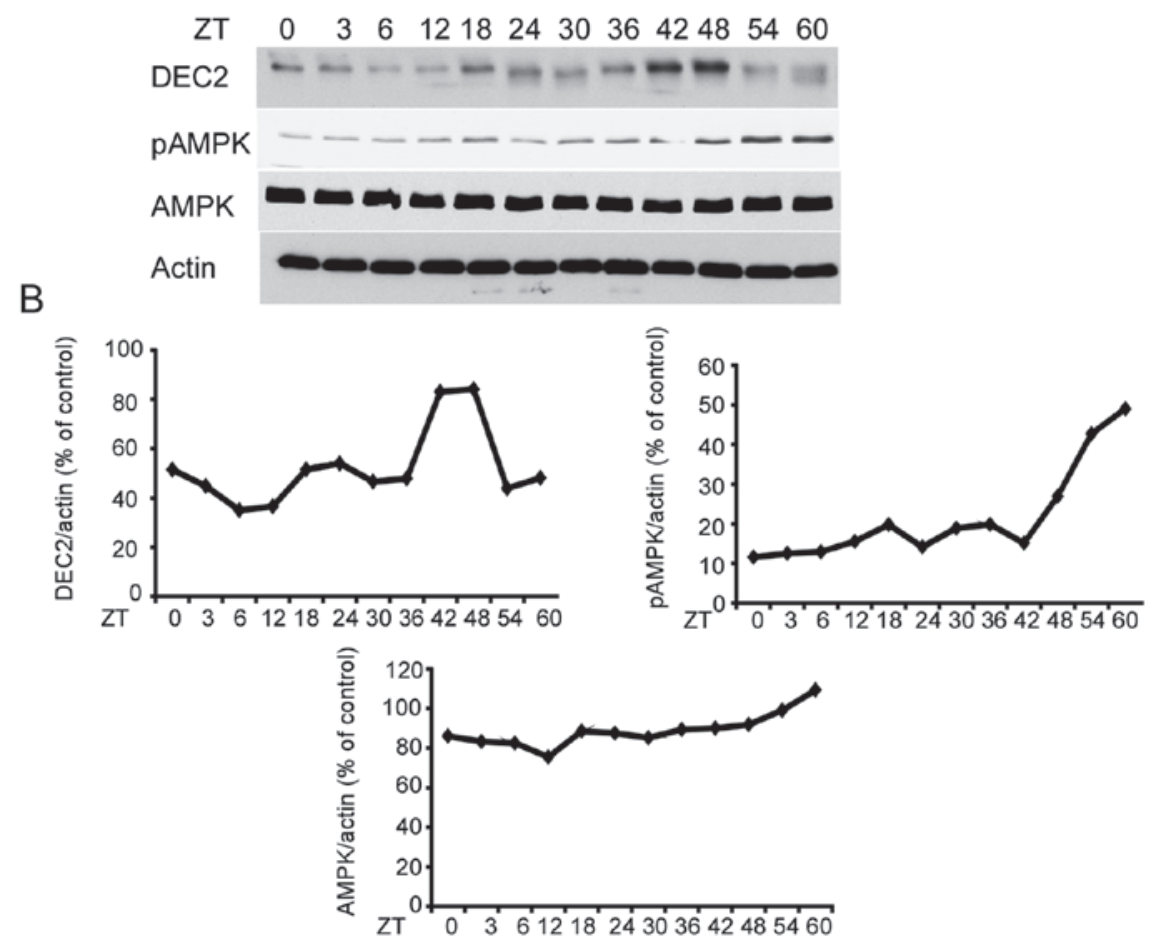

C

MCF-7

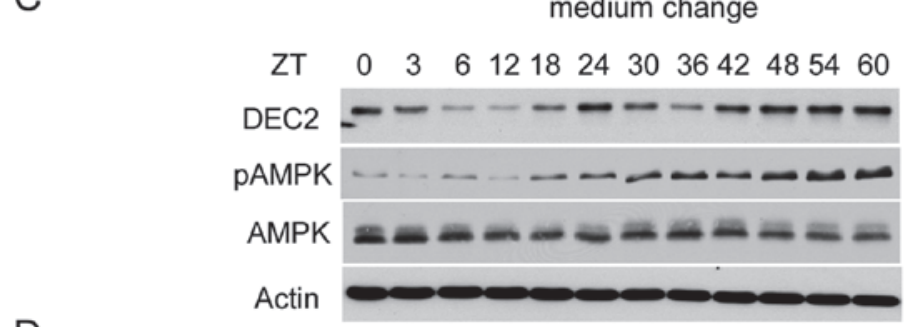

D
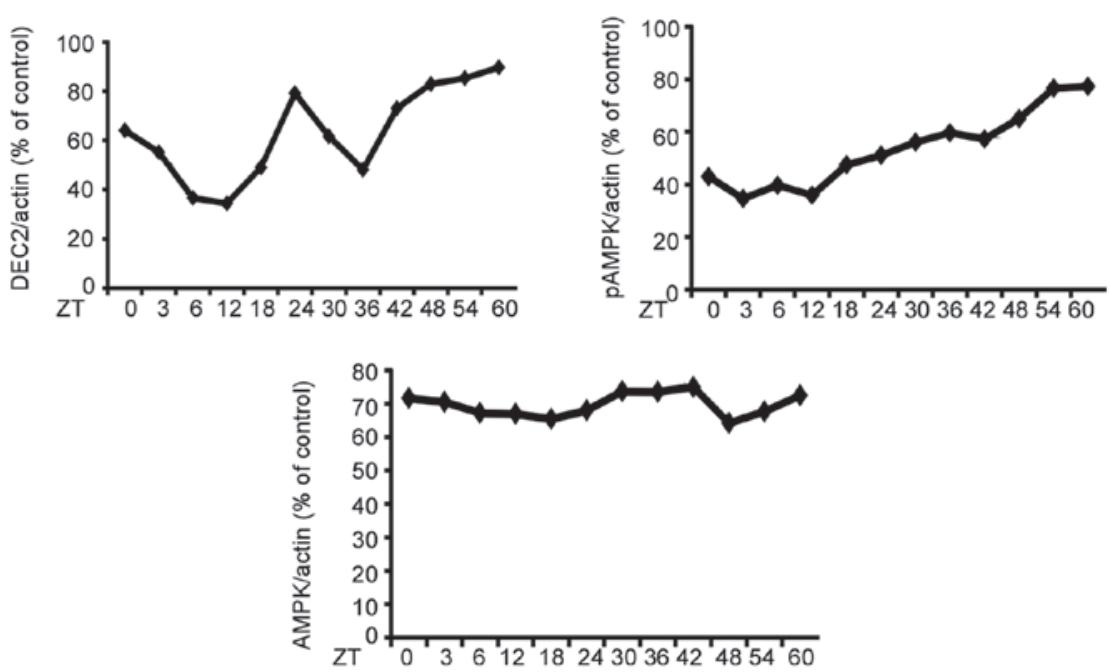

Figure 2. Rhythmic expression of DEC2 protein in U2OS and MCF-7 cells by the medium change. (A and B) U2OS and (C and D) MCF-7 cells were cultured and subjected to a medium change. The cells were sampled at 0 and $3 \mathrm{~h}$ and then every $6 \mathrm{~h}$ until $60 \mathrm{~h}$. Samples were subjected to western blotting for DEC2, pAMPK, AMPK and actin levels. One representative sample from two independent experiments with similar results is shown. The intensities of DEC2, pAMPK and AMPK bands were quantified as described above. AMPK, AMP-activated protein kinase.

endogenous DEC2 expression in a rhythmic manner, resetting the circadian clock in U2OS and MCF-7 cells.
We also found that pAMPK increased in cultured cells at a later stage after medium change, although a rhythmic 
A

WT MEF

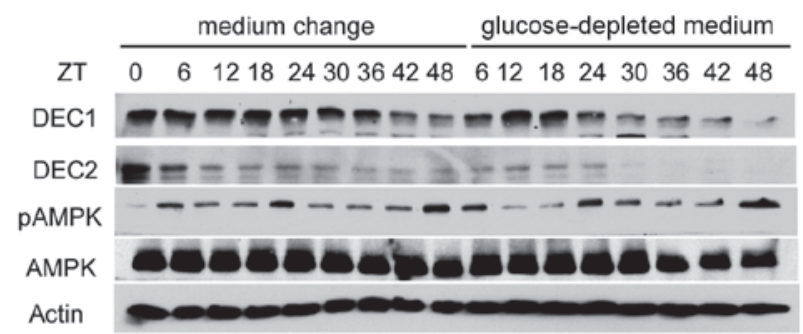

B
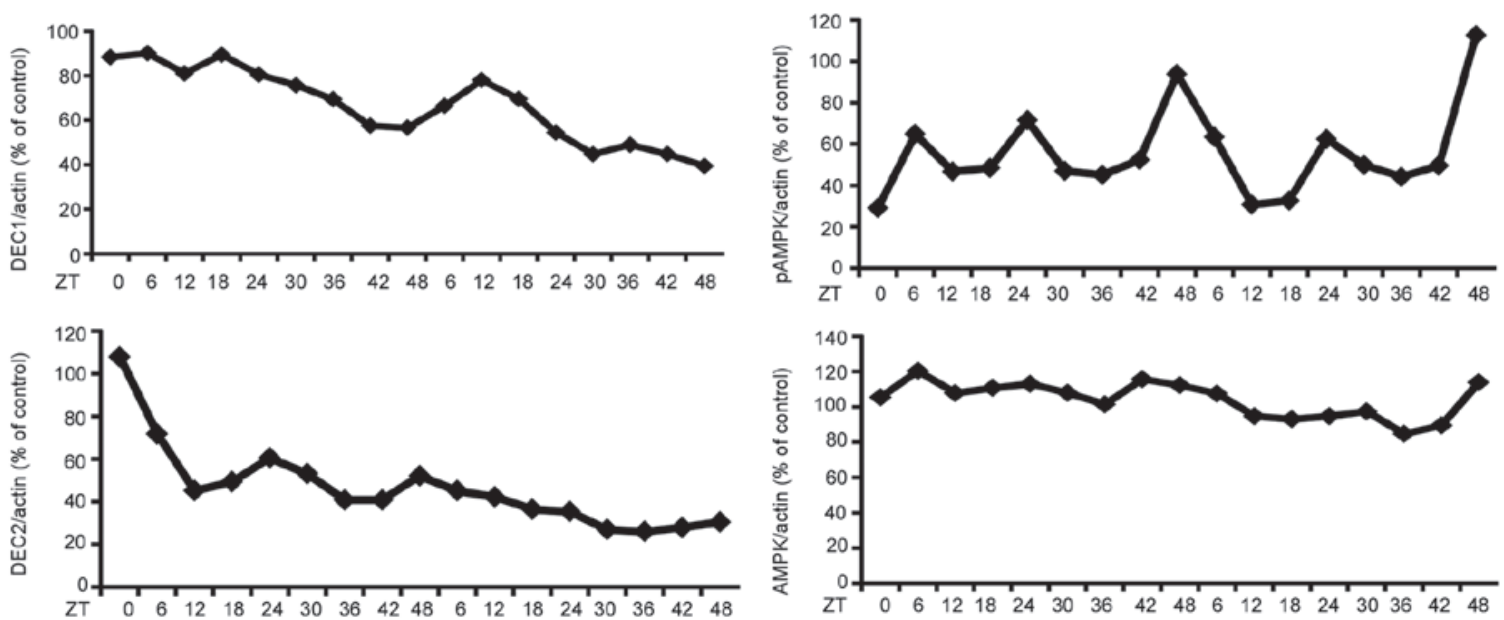

Figure 3. Rhythmic expression of DEC2 protein in MEF is decreased by medium change. (A) MEF were cultured and subjected to medium change or glucose-depleted medium. The cells were sampled at 0 and $6 \mathrm{~h}$ and then every $6 \mathrm{~h}$ until $48 \mathrm{~h}$ from the time of the medium change $(0 \mathrm{~h})$ or glucose-depleted medium. Samples were subjected to western blotting for DEC1, DEC2, pAMPK, AMPK and actin levels. One representative sample from two independent experiments with similar results is shown. (B) The intensities of DEC1, DEC2, pAMPK and AMPK bands were quantified as described above. MEF, mouse embryonic fibroblast; AMPK, AMP-activated protein kinase.

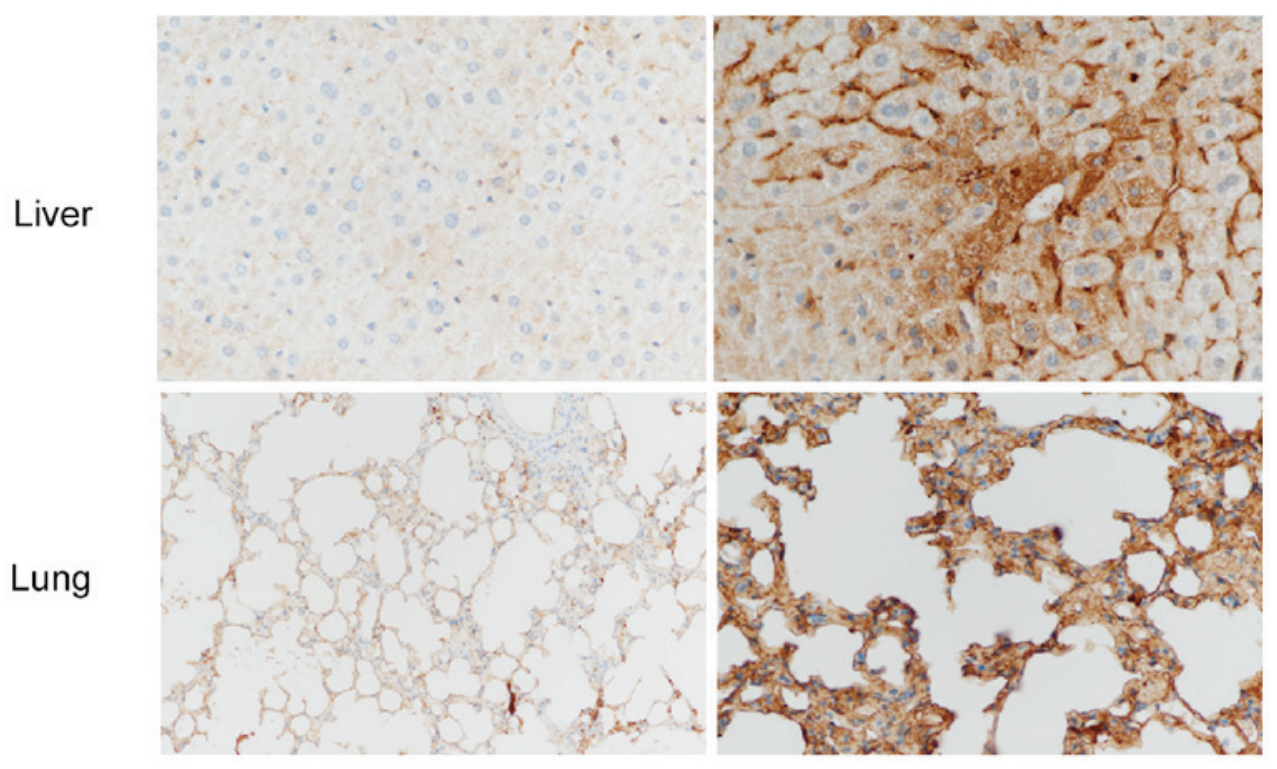

Figure 4. pAMPK immunoreactivity was strongly detected in DEC2 knockout mice tissues. Strong pAMPK immunoreactivity was detected in the liver and lung of DEC2 KO mice compared with WT mice. AMPK, AMP-activated protein kinase; KO, knockout; WT, wild-type.

expression was not observed. Considering that cancer cells consume much glucose compared with normal cells, an increase of pAMPK observed in cancer cells may be associated with glucose condition where pAMPK is known to be induced by glucose depletion (32). Of note, pAMPK in MEF showed a rhythmic expression under the condition of medium 
change or glucose-depleted medium. This result suggests that medium change reset the circadian clock, inducing rhythmic expression. It is possible that the effect on the reset of the circadian clock by medium change may differ in cell types. Future studies are required to clarify the different effects on other types of cells.

The rhythmic expression of DEC2 protein in MEF was not clear compared with that in U2OS and MCF-7 cells. Since MEF are undifferentiated cells, it is possible that DEC2 may show a rhythmic expression in differentiated cells, although the rhythmic expression of DEC2 may decrease in undifferentiated cells.

In conclusion, we have demonstrated a rhythmic expression of DEC2 protein. In addition, pAMPK in MEF has shown the rhythmic expression under the condition of medium change or glucose-depleted medium. These results provide new aspects of DEC2 protein and AMPK activity in culture cells.

\section{Acknowledgements}

We would like to thank Shenli Hew from the Department of Clinical Research Center, Wakayama Medical University, for proofreading and editing the manuscript. The present study was supported by grants (CA100302) from the NIH awarded to Y.Z., a Grant-in-Aid for Scientific Research (24590488) from the Ministry of Education, Science, Sport, and Culture of Japan awarded to Y.M., and from the Special Research Project of Wakayama Medical University School of Medicine awarded to F.S.

\section{References}

1. Merrow M, Spoelstra K and Roenneberg T: The circadian cycle: Daily rhythms from behaviour to genes. EMBO Rep 6: 930-935, 2005.

2. Gekakis N, Staknis D, Nguyen HB, Davis FC, Wilsbacher LD, King DP, Takahashi JS and Weitz CJ: Role of the CLOCK protein in the mammalian circadian mechanism. Science 280 1564-1569, 1998.

3. Honma S, Kawamoto T, Takagi Y, Fujimoto K, Sato F, Noshiro M, Kato Y and Honma K: Dec1 and Dec2 are regulators of the mammalian molecular clock. Nature 419: 841-844, 2002.

4. Turek FW: From circadian rhythms to clock genes in depression. Int Clin Psychopharmacol 22 (Suppl 2): S1-S8, 2007.

5. Marcheva B, Ramsey KM, Buhr ED, Kobayashi Y, Su H, Ko CH, Ivanova G, Omura C, Mo S, Vitaterna MH, et al: Disruption of the clock components CLOCK and BMAL1 leads to hypoinsulinaemia and diabetes. Nature 466: 627-631, 2010.

6. Turek FW, Joshu C, Kohsaka A, Lin E, Ivanova G, McDearmon E, Laposky A, Losee-Olson S, Easton A, Jensen DR, et al: Obesity and metabolic syndrome in circadian Clock mutant mice. Science 308: 1043-1045, 2005.

7. Parent MÉ, El-Zein M, Rousseau MC, Pintos $\mathrm{J}$ and Siemiatycki J: Night work and the risk of cancer among men. Am J Epidemiol 176: 751-759, 2012.

8. He Y, Jones CR, Fujiki N, Xu Y, Guo B, Holder JL Jr, Rossner MJ, Nishino $\mathrm{S}$ and Fu YH: The transcriptional repressor DEC2 regulates sleep length in mammals. Science 325: 866-870, 2009.

9. Rosen G and Brand SR: Sleep in children with cancer: Case review of 70 children evaluated in a comprehensive pediatric sleep center. Support Care Cancer 19: 985-994, 2011.

10. Wu Y, Sato F, Bhawal UK, Kawamoto T, Fujimoto K, Noshiro M, Morohashi S, Kato Y and Kijima H: Basic helix-loop-helix transcription factors DEC1 and DEC2 regulate the paclitaxel-induced apoptotic pathway of MCF-7 human breast cancer cells. Int J Mol Med 27: 491-495, 2011.
11. Wu Y, Sato F, Yamada T, Bhawal UK, Kawamoto T, Fujimoto K, Noshiro M, Seino H, Morohashi S, Hakamada K, et al: The BHLH transcription factor DEC1 plays an important role in the epithelial-mesenchymal transition of pancreatic cancer. Int $\mathrm{J}$ Oncol 41: 1337-1346, 2012.

12. Kohsaka A, Laposky AD, Ramsey KM, Estrada C, Joshu C, Kobayashi Y, Turek FW and Bass J: High-fat diet disrupts behavioral and molecular circadian rhythms in mice. Cell Metab 6: 414-421, 2007.

13. Kohsaka A, Das P, Hashimoto I, Nakao T, Deguchi Y, Gouraud SS, Waki H, Muragaki Y and Maeda M: The circadian clock maintains cardiac function by regulating mitochondrial metabolism in mice. PLoS One 9: e112811, 2014.

14. Sun H, Lu B, Li RQ, Flavell RA and Taneja R: Defective T cell activation and autoimmune disorder in Stra13-deficient mice. Nat Immunol 2: 1040-1047, 2001.

15. Papagerakis S, Zheng L, Schnell S, Sartor MA, Somers E, Marder W, McAlpin B, Kim D, McHugh J and Papagerakis P: The circadian clock in oral health and diseases. J Dent Res 93: 27-35, 2014.

16. Baier PC, Brzózka MM, Shahmoradi A, Reinecke L, Kroos C, Wichert SP, Oster H, Wehr MC, Taneja R, Hirrlinger J, et al: Mice lacking the circadian modulators SHARP1 and SHARP2 display altered sleep and mixed state endophenotypes of psychiatric disorders. PLoS One 9: e110310, 2014.

17. Sato F, Kawamoto T, Fujimoto K, Noshiro M, Honda KK, Honma S, Honma K and Kato Y: Functional analysis of the basic helix-loop-helix transcription factor DEC1 in circadian regulation. Interaction with BMAL1. Eur J Biochem 271: 4409-4419, 2004.

18. Kawamoto T, Noshiro M, Sato F, Maemura K, Takeda N, Nagai R, Iwata T, Fujimoto K, Furukawa M, Miyazaki K, et al: A novel autofeedback loop of Decl transcription involved in circadian rhythm regulation. Biochem Biophys Res Commun 313: 117-124, 2004.

19. Noshiro M, Furukawa M, Honma S, Kawamoto T, Hamada T, Honma K and Kato Y: Tissue-specific disruption of rhythmic expression of Dec1 and Dec2 in clock mutant mice. J Biol Rhythms 20: 404-418, 2005.

20. Miyazaki K, Kawamoto T, Tanimoto K, Nishiyama M, Honda H and Kato Y: Identification of functional hypoxia response elements in the promoter region of the DEC1 and DEC2 genes. J Biol Chem 277: 47014-47021, 2002.

21. Sato F, Bhawal UK, Kawamoto T, Fujimoto K, Imaizumi T, Imanaka T, Kondo J, Koyanagi S, Noshiro M, Yoshida H, et al: Basic-helix-loop-helix (bHLH) transcription factor DEC2 negatively regulates vascular endothelial growth factor expression. Genes Cells 13: 131-144, 2008.

22. Iwata T, Kawamoto T, Sasabe E, Miyazaki K, Fujimoto K, Noshiro M, Kurihara H and Kato Y: Effects of overexpression of basic helix-loop-helix transcription factor Dec1 on osteogenic and adipogenic differentiation of mesenchymal stem cells. Eur J Cell Biol 85: 423-431, 2006.

23. Sato F, Kawamura H, Wu Y, Sato H, Jin D, Bhawal UK, Kawamoto T, Fujimoto K, Noshiro M, Seino H, et al: The basic helix-loop-helix transcription factor DEC2 inhibits TGF- $\beta$-induced tumor progression in human pancreatic cancer BxPC-3 cells. Int J Mol Med 30: 495-501, 2012.

24. Turley H, Wykoff CC, Troup S, Watson PH, Gatter KC and Harris AL: The hypoxia-regulated transcription factor DEC1 (Stra13, SHARP-2) and its expression in human tissues and tumours. J Pathol 203: 808-813, 2004.

25. Matsunaga N, Inoue M, Kusunose N, Kakimoto K, Hamamura K, Hanada Y, Toi A, Yoshiyama Y, Sato F, Fujimoto K, et al: Time-dependent interaction between differentiated embryo chondrocyte-2 and CCAAT/enhancer-binding protein $\alpha$ underlies the circadian expression of CYP2D6 in serum-shocked HepG2 cells. Mol Pharmacol 81: 739-747, 2012.

26. Sato F, Sato H, Jin D, Bhawal UK, Wu Y, Noshiro M, Kawamoto T, Fujimoto K, Seino H, Morohashi S, et al: Smad3 and Snail show circadian expression in human gingival fibroblasts, human mesenchymal stem cell, and in mouse liver. Biochem Biophys Res Commun 419: 441-446, 2012.

27. Sato F and Muragaki Y: Circadian expression of DEC1, SMAD3 and SNAIL in human mesenchymal stem cells. J Stem Cells Res, Rev \& Rep 1: 1-3, 2014.

28. Oishi K, Koyanagi S and Ohkura N: Circadian mRNA expression of coagulation and fibrinolytic factors is organdependently disrupted in aged mice. Exp Gerontol 46: 994-999, 2011. 
29. Nakashima A, Kawamoto T, Honda KK, Ueshima T, Noshiro M Iwata T, Fujimoto K, Kubo H, Honma S, Yorioka N, et al: DEC1 modulates the circadian phase of clock gene expression. Mol Cell Biol 28: 4080-4092, 2008.

30. Hardie DG: AMP-activated protein kinase: an energy sensor that regulates all aspects of cell function. Genes Dev 25: 1895-1908, 2011.

31. Cantó C and Auwerx J: AMP-activated protein kinase and its downstream transcriptional pathways. Cell Mol Life Sci 67: 3407-3423, 2010.

32. Mihaylova MM and Shaw RJ: The AMPK signalling pathway coordinates cell growth, autophagy and metabolism. Nat Cel Biol 13: 1016-1023, 2011.

33. Yun H, Kim HS, Lee S, Kang I, Kim SS, Choe W and Ha J: AMP kinase signaling determines whether $\mathrm{c}$-Jun $\mathrm{N}$-terminal kinase promotes survival or apoptosis during glucose deprivation. Carcinogenesis 30: 529-537, 2009.

34. Um JH, Pendergast JS, Springer DA, Foretz M, Viollet B, Brown A, Kim MK, Yamazaki S and Chung JH: AMPK regulates circadian rhythms in a tissue- and isoform-specific manner. PLoS One 6: e18450, 2011.

35. Lamia KA, Sachdeva UM, DiTacchio L, Williams EC, Alvarez JG, Egan DF, Vasquez DS, Juguilon H, Panda S, Shaw RJ, et al: AMPK regulates the circadian clock by cryptochrome phosphorylation and degradation. Science 326: 437-440, 2009.

36. Sato F, Muragaki Y and Zhang Y: DEC1 negatively regulates AMPK activity via LKB1. Biochem Biophys Res Commun 467: 711-716, 2015.

37. Clegg HV, Itahana $\mathrm{Y}$, Itahana $\mathrm{K}$, Ramalingam $\mathrm{S}$ and Zhang $\mathrm{Y}$ Mdm2 RING mutation enhances p53 transcriptional activity and p53-p300 interaction. PLoS One 7: e38212, 2012.

38. Noshiro M, Kawamoto T, Furukawa M, Fujimoto K, Yoshida Y, Sasabe E, Tsutsumi S, Hamada T, Honma S, Honma K, et al: Rhythmic expression of DEC1 and DEC2 in peripheral tissues: DEC2 is a potent suppressor for hepatic cytochrome P450s opposing DBP. Genes Cells 9: 317-329, 2004.
39. Wu T, Ni Y, Zhuge F, Sun L, Xu B, Kato H and Fu Z: Significant dissociation of expression patterns of the basic helix-loop-helix transcription factors Dec1 and Dec2 in rat kidney. J Exp Biol 214: 1257-1263, 2011.

40. Choi SM, Cho HJ, Cho H, Kim KH, Kim JB and Park H: Stra13/DEC1 and DEC2 inhibit sterol regulatory element binding protein-1c in a hypoxia-inducible factor-dependent mechanism. Nucleic Acids Res 36: 6372-6385, 2008.

41. Azmi S, Ozog A and Taneja R: Sharp-1/DEC2 inhibits skeletal muscle differentiation through repression of myogenic transcription factors. J Biol Chem 279: 52643-52652, 2004.

42. Tanoue S, Fujimoto K, Myung J, Hatanaka F, Kato Y and Takumi T: DEC2-E4BP4 heterodimer represses the transcriptional enhancer activity of the EE element in the Per2 promoter. Front Neurol 6: 166, 2015. doi: 10.3389/fneur.2015.00166.

43. Nakamura H, Tanimoto K, Hiyama K, Yunokawa M, Kawamoto T, Kato Y, Yoshiga K, Poellinger L, Hiyama E and Nishiyama M: Human mismatch repair gene, MLH1, is transcriptionally repressed by the hypoxia-inducible transcription factors, DEC1 and DEC2. Oncogene 27: 4200-4209, 2008.

44. Hirota T, Okano T, Kokame K, Shirotani-Ikejima H, Miyata T and Fukada Y: Glucose down-regulates Perl and Per2 mRNA levels and induces circadian gene expression in cultured Rat-1 fibroblasts. J Biol Chem 277: 44244-44251, 2002.

45. Liu Y, Sato F, Kawamoto T, Fujimoto K, Morohashi S, Akasaka H, Kondo J, Wu Y, Noshiro M, Kato Y, et al: Anti-apoptotic effect of the basic helix-loop-helix (bHLH) transcription factor DEC2 in human breast cancer cells. Genes Cells 15: 315-325, 2010.

46. Hu T, He N, Yang Y, Yin C, Sang N and Yang Q: DEC2 expression is positively correlated with HIF-1 activation and the invasiveness of human osteosarcomas. J Exp Clin Cancer Res 34: 22,2015 . 